\title{
Competitiveness
}

\section{as an educational tool}

\author{
Fernando Llopis Pascual \\ Departamento de Lenguajes y Sistemas Informáticos \\ Universidad de Alicante \\ Alicante, Spain \\ fernando.1lopis@ua.es
}

\begin{abstract}
Continuous changes in the real world implies the need of change in the curriculums of the students. Aspects such as leadership, team management, competitiveness, may be more important than the technical knowledge. On the other hand, new demands require a symbiotic relationship between business and university. In the article it presents an experience of a real integration project lead by professionals in the classroom.
\end{abstract}

Keywords-component; Software Engineering, Business, Competitiveness

\section{INTRODUCTION}

Prophetically, the President of Telefonica, Cesar Alierta said in a conference about the necessary digitization of our world, "in the next 10 years, $65 \%$ of high school students will work in jobs that not exist today.

The digital world has changed significantly our "real world". Companies in Europe are demanding thousands of well-trained professionals. When it happens, everyone looks to the University. The university is the responsible to train young Europeans. At this critical moment, at the University, often we spend our time in sterile debates. I think we should think about what the needs of our society. We must think about the role to be played by the European University Education changes. We must think as our university can improve the training of young people in the coming decades. "Academic excellence and quality are key elements in Higher Education. To benefit from globalization is necessary to strengthen the bargaining power, integration and competitiveness of universities. " [1]

Keep in mind also, as indicated [8] "However, Europe does not realize that what evolves the University and in science in the United States isn't the money, the key is the competition between the people."

Therefore, in technological university studies should lead to an increasingly important effort to change in the digital production model. The curriculum changes significantly since the student began his studies until he ends. On one hand, greater flexibility in adapting to the needs of content is required.

On the other side there have been notable advances is in adapting eLearning models. Teachers have abandoned the concept of online and traditional teaching for a new model. In this model is common to use both depending on the needs of students [2]

At the University we are being quite receptive to the change of educational model, but despite the great efforts made [3], I understand that is necessary to approach the world of real work in training students. We must overcome the model in which companies only hire college students because they consider that students are capable of having passed some tests of some complexity and have a greater capacity for learning, and after form them into tools that their employees often use. Universities often organize conferences with companies or job fairs. Unfortunately, many times only to clear his conscience. I think there we must build a beneficial project for both institutions. It is essential a greater involvement of enterprises in the training of students. I am sure that involvement can be enormously beneficial to both parties. On the one hand, it allows college students can know the working models used as well as companies allows them to meet outstanding students.

Work in well-managed group may be certainly a training aid for students. It is a model that has always given good results. But I think it's important to add competitiveness. Competition has always existed among students. But I think the competitiveness is a key element of training. Competitiveness can produce very interesting and beneficial results.

This competition among students requires them to overcome the challenges identified by the teacher, in addition also requires them to overcome the work of the other teams.

In this paper it presents the teaching model of a subject in the third year of Computer Engineering. In this project have 
participated active IT companies. Professionals of these companies have participated as Product Manager or Product Owner in a team of students. Student teams competed with each other to be the best in the development of a real application.

\section{SCRUM}

The Technical Specification Software course (TAES) is taught in the second semester of the third year of the degree in Computer Engineering in the itinerary of Software Engineering. It is a subject of 6 credits, which means four hours of classroom teaching in the classroom. Half of them are theoretical credits and the other half are practical.

In TAES is presented a number of keys aspects for the efficient development of software such as teamwork development as well as software development methodologies.

The base is that a development of a complex software development will be more successful if the tasks of previous analysis and planning is done properly. Another important idea is "No one is better than all of us together".

This course is a natural continuation of the Analysis and Specification of Software Systems but is intrinsically related to other subjects Application Development and Database Design.

While in other subjects of the specialty the focus is on basic concepts of Software Engineering, TAES gives emphasis on development team management. In this way is incorporating into the program not only aspects of requirements definition or specification of information systems but useful techniques as meeting management, customer interviews, as well as aspects of leadership, negotiation techniques and effective public presentations.

The methodology used during the course have been agile development methodologies [4], focusing especially on the SCRUM [5] methodology. These methodologies are based on iterative and incremental software development. Agile methodologies incorporate a number of roles among which that of Product Owner, the Scrum Master and the Development Team or Development Team.

The Product Owner is one person, and is taking responsibility to determine which product must be developed, although it may obviously have to make inquiries to others. In a way it is a kind of Product Manager (interesting comparison of both roles in [6], although it has these leaderships over the rest of the team.

The Development Team consists of a group of professionals responsible for designing and implementing the product to perform. The team must perform the sprints (periods with a goal). They are responsible for the work done properly.

Finally, the Scrum Master is responsible for the team to work according to the Scrum rules.

The Development Team structure allows them to organize and manage their own work. This breaks the traditional pattern in which a Product Manager give orders each of the team members, this orders determine the development to be undertaken.
The main characteristics that define Scrum teams is that they are self-organizing, i.e. are directed from the same team. That self-organization is essential in the process of student learning, are they who must guide their product development. The concept of "self-organization" is a concept that is repeated over and over again during the course.

The application of all concepts is managed through the practical part of the course, comprising two hours a week by person. It has been divided into two distinct deliveries, first practice is a "warm" and a second where a very large group of students aims to emulate a real project. These two practices are different in terms of statements, address and number of members of groups that must be carried. In the first practice the students propose the work they will perform. The groups are formed by 5 students. The management team is completely self-organized. In the second practice, the teacher proposes a same problem to solve by each group. An employee of a partner company acts as Product Owner. The number of team members is the total number of students in each group practices (17-20).

\section{OBJETIVES}

There are a number of aspects to be fundamentally enhance the subject. They are as follows and are discussed in the following sections:

\section{A. Innovation}

The two practices to deliver tasks involve specification, design and development. Although the central part of the design practice, we understand that the implementation of appropriate finished product is made so that it can validate design tasks. The first practice has a maximum number of individual components. Proposals to develop practice are performed and presented individually by each student.

Then, in each practice groups (on five components per group) group members must choose from the five individual proposals for each of the members which is the most convenient to develop formed. They should also give reasons for their choice

The student whose proposal is chosen obtains better qualification than the rest of components. This generates additional motivation, and not only to define the best proposal the group, but by properly defend against other proposals made by the group members.

It affects an interesting dilemma at this time. A group can choose as a proposal to develop if so desired, by a student from another group who has not chosen as a proposal to develop.

Thus, each component must defend its proposal, on the one hand, in order to obtain better note, but on the other hand should also appreciate that, if you do not choose the best proposal of all those presented in the group, the group project may fall behind the rest in the final presentation.

This dilemma is adequately explained to adequately assess students choosing to take. During this course, the student must motivate the project has been chosen to develop in way quite justified and reasonable. 


\section{B. Teamwork}

The development of practice allows to know the team on their way to final objective. Students define tasks and sprints (deadlines for each task as Scrum terminology). It is said that the correct task decomposition is essential. It is also said that each task should be assigned to a team member. The concept "commitment to the team" is repeated over and over again, and tracking an individual work of each is performed.

\section{Company in the University}

The proposed collaboration to three companies was as follows: They were asked to one of his employees act as Product Owner or Product Manager of each of the groups of practices of the subject. They were also asked to act as support if necessary, especially in the recommendation to use development tools. The advantages of this collaboration for business are many. I understand that are indubitable. First and companies can help in the learning process for students. Students will complete their studies next year. TAES is a third year course (in Spain the engineering is four courses).

The company may offer to good students is a chance to do internships in business next year while study in fourth grade.

Within a recruitment process, when there needs of professional well trained as in the current situation, it is a great opportunity that prior knowledge of the candidates within your studio environment. On the other hand, students are allowed to know first-hand the working methods used by companies in the area and may be disclosed to them in order to obtain a job in a short space of time. Thus, we achieve a real interactive making contact between company and student when he is about to complete its university stage.

As a downside, this model involves for participating companies a number of "non-billable" hours. This is very important. It also generated in a student doubts about whether having companies obtain a profit on the project. This concern was initially eliminated in stating that this was merely a practice that had the collaboration of professionals from companies, and in any case would be developed proprietary product

The course had three groups of about 20 students. We contacted three distinct companies, a traditional consulting firm, a micro multinational and a new technology company. The call was a success as all three agreed to this collaboration. This reinforces the idea that if things get easier and the projects are well explained, the Business-University collaboration is possible.

The project generated some initial doubts in the heads of the companies on competitiveness that would produce between them. It is obvious that inevitably would produce comparisons between the work of the three groups. In fact, a company wanted to manage the three groups. I understood that it was better enhance the competitiveness not only among students but among businesses. Also the students could meet with different working models. (In the early days of course each company made an initial presentation in explaining its working model).

\section{Communication}

It has been one of the aspects that attracted initial reticence in the student. Successfully the students at the end of the course has rated as one of the most important. One of the great problems of teamwork is precisely the lack of real group work.

Students often divide the work but for practical subjects. This makes the experience that we try to involve the student does not achieve the stated objectives. As an initial modulation, the first practice was a common scheme group of five people, which as a professor trying to keep track of work done by each student.

In practice two, problem is very complex because the groups are twenty students. Each group divided the work into smaller tasks (as in a real project) but it increases communication problems. Each sub group must communicate with the rest, also must know the state of interconnected tasks.

Except for some students who are already incorporated into the working world, for almost all has been the first experience of working in such a large group. It has been interesting and gratifying meetings that each of the subgroups have maintained.

\section{E. Leadership}

It is an aspect that may pass unnoticed by students as a value in its curriculum.

In groups with clear leadership the results have been better than the rest. That leadership, which generally tends to be supported by the rest of the group, means that there is a reference that facilitates solving problems or unblock difficult situations that sometimes occur when the interests of the students are not exactly the same. It was striking that show leadership drew the attention of the employees of the company more than other purely technical factors. I think that leadership should be strengthened in the classroom as a most important aspect of student training, thus exceeding the phrase Daniel Goleman [7] "The academic intelligence offers the least preparation for the multitude of opportunities, or difficulties - to which we face throughout our life".

\section{F. Competitiveness}

It is an aspect that is very important in this course.

"No matter only if you do ok, you must do better than others, it is the only way to compare if your work is good" is the lemma of course. That competitiveness has reached extremes of some interest is usual in this course. In one of the sessions presenting job requirements to make it opted for a generic proposal without details, and had a subject matter expert client that was willing to respond to questions from the students.

In the example this year we decided to develop a system that would allow a public administration promote "running" (sport).

In one of the sessions he attended an expert in Running to detail advantages and disadvantages of existing applications. After his presentation, students were allowed to make a round of questions, first with all the groups present and then specifically for each group.

In the first case there were no questions, and each and every one of the groups carried on their turn. Nobody wanted to give clues to other group which would be its proposed improvements. 


\section{EVALUATION}

This evaluation was performed with the heads of companies, as well as a questionnaire to students.

\section{A. Comapnies}

Companies have expressed their satisfaction with the experience and desire to continue next year. The biggest problem that they have had has been the difficulty of attending some sessions due to travel or other work.

I wish that Spanish companies detects is very important to collaborate with the University in the training process. When this happens companies will devote more time to the University.

\section{B. Students}

The greatest concern of the students has been the number of hours that have had to devote to the project. It is a common complaint in this type of work. Perhaps in this case it was offset by the fact that it was not necessary to conduct a review of theory.

Business experience has been valued positively practically unanimously. There is a noticeable desire in students getting a job they like. One of the most valued aspects has been the project 2, which has forced them to an additional effort of communication between them, but they have managed to solve noticeably. Finally, many of them say that the obligation to learn to develop for mobile devices has been tough but highly satisfactory.

TABLE I. EVALUATION

\begin{tabular}{|l|l|c|c|c|}
\hline & Grupo I & Grupo II & Grupo III & Media \\
\hline Model witx extarnal tutors & 7.94 & 8.46 & 8.9 & 8.43 \\
\hline
\end{tabular}

Fig. 1. Students evaluation

\section{CONCLUSIONS AND FUTURE WORKS}

In reviewing the work done by the students I have some optimism about what they can do with motivation and long enough. The concept of developing a real application, with real customers, real leaders, real competition, has managed to strengthen a number of theoretical knowledge that can only be settled through practice. The details of the interview in which each group did not want to publicize what their concerns were the other groups do that shows that the competitive concept is important for students in this subject.

The existence of a leadership in the group has been an important factor in obtaining success factor at work. Interestingly these figures leaders within teams have been one of the details that have drawn attention to the professionals who have collaborated in the course. That is why one of the clearest need for training components are concepts of leadership and team management, beyond the technical expertise that too often we become obsessed to learn.

Students have managed to learn working models and tools commonly used in the professional world have also had the opportunity to be real actors in business motivation sessions or deadlines are set. The goal is to continue next year with the same educational model year. I want to conduct a study of whether there has been recruiting students

\section{ACKNOWLEDGEMENTS}

Acknowledgements This research work has been partially funded by the University of Alicante, Generalitat Valenciana, Spanish Government and the European Commission through the projects, DIIM2.0 (PROMETEOII/2014/001) de la Generalitat Valenciana, TIN2015-65100-R, TIN2015-65136-C2-2-R del Ministerio de Economía y Competitividad y SAM (FP7-611312) de la Unión Europea

Thanks to Gemalto, Everis and SolidQ for their collaboration in this course.

\section{REFERENCES}

[1] R. Salas La calidad en el desarrollo profesional: avances y desaf' 10 , : Educacion M' edica Superior v.14 n.2 Ciudad de la Habana Mayo-ago. ' 2000

[2] F. Jose Garc ' '1a-Penalvo and A. Seoane Pardo Una revision actualizada del' concepto de eLearning, Education in the Knowledge Society Ediciones Universidad de Salamanca 2015

[3] Agudo Peregrina and Angel Francisco ' De la idea a la empresa Everis Documents 2015

[4] Kent Beck et al Agile Manifesto . http://agilemanifesto.org/, 2001.

[5] Jeff Sutherland. Scrum: El nuevo y revolucionario modelo organizativo que cambiara tu vida. ' Ed Planeta 2015

[6] Steve resnick et al.Professional Scrum with Team Foundation Server 2010 Ed. Wrox Press 2011

[7] Daniel Goleman. Liderazgo. El poder de la inteligencia emocional Ed B 2013.

[8] Ken Schawabber The Scrum development process OOPSLA '95 Workshop on Business Object Design and Implementation, Austin, 1995.

[9] Angel Gomez Montoro Posibilitar la competitividad para mejorar la calidad Blog Universidad Studi XXI, 2105 